\title{
"Quem Sabe de Mim Sou Eu": práticas culturais e comunicacionais como instrumentos pedagógicos junto a jovens em vulnerabilidade
}

DOI: https://doi.org/10.22409/pragmatizes.v11i20.45794

\author{
Flora Daemon ${ }^{1}$ \\ Kleber Mendonça ${ }^{2}$ \\ Marildo José Nercolini ${ }^{3}$
}

Resumo: O presente artigo propõe uma reflexão teórico-metodológica a partir da experiência acumulada no âmbito de um projeto universitário de caráter extensionista que, ao longo dos últimos oito anos, promove atividades voltadas para jovens em situação de vulnerabilidade social. Ao apresentar as ferramentas usadas e refletir sobre as questões e desafios enfrentados, buscamos desenvolver uma metodologia que seja capaz de acessar esses jovens. Nossa meta é explicitar como é possível articular práticas culturais e ferramentas comunicacionais, capazes de contribuir para um processo de subjetivação emancipador, com a finalidade de desarmar "profecias autorrealizáveis", comuns às trajetórias desses jovens. Acionamos, ao longo de nossa atuação, modos potentes de trazer para o plano do visível a experiência, a memória, a corporalidade e a fala como possibilidades de expressão das subjetividades singulares desses jovens, ainda assim constantemente atravessadas por relações de poder estruturais, violentas e hierárquicas.

Palavras-Chave: Cultura e educação; favela; juventude; universidade; extensionismo.

\footnotetext{
${ }^{1}$ Flora Côrtes Daemon de Souza Pinto. Doutora em Comunicação pela Universidade Federal Fluminense, professora Adjunta do curso de Jornalismo da Universidade Federal Rural do Rio de Janeiro (UFRRJ), Brasil. Email: floradaemon@yahoo.com.br - https://orcid.org/0000-0001-9652-1748

${ }^{2}$ Kleber Santos de Mendonça. Doutor em Comunicaçãopela Universidade Federal Fluminense, professor Associado do Departamento de Estudos Culturais e Mídia e dos Programas de PósGraduação em Comunicação (PPGCOM) e em Cultura e Territorialidades (PPCULT) da Universidade Federal Fluminense (UFF), Niterói/RJ, Brasil. Email: klebermendonca@id.uff.br https://orcid.org/0000-0001-8055-7447

${ }^{3}$ Marildo José Nercolini. Doutor em Ciência da Literatura (UFRJ 2005), Professor Associado do Departamento e Estudos Culturais e Mídia (GEC/IACS) e do Programa de Pós-Graduação em Cultura e Territorialidades (PPCULT) da Universidade Federal Fluminense (UFF), Niterói/RJ, Brasil. Email: mjnercolini@gmail.com - https://orcid.org/0000-0003-0465-0011
} 
Niterói/RJ, Ano 11, n. 20, p. 109-135, março 2021.

"Quem Sabe de Mim Sou Eu": prácticas culturales y comunicativas como herramientas pedagógicas para jóvenes vulnerables

Resumen: Este artículo propone una reflexión teórico-metodológica a partir de la experiencia acumulada en el ámbito de un proyecto universitario de extensión que, durante los últimos ocho años, promueve actividades dirigidas a jóvenes en situación de vulnerabilidad social. Al presentar las herramientas utilizadas y reflexionar sobre los problemas y desafíos enfrentados, buscamos desarrollar una metodología que sea capaz de acceder a estos jóvenes. Nuestro objetivo es explicar cómo es posible articular prácticas culturales y herramientas de comunicación, capaces de contribuir a un proceso de subjetivación emancipatorio, con el propósito de desarmar "profecías autocumplidas", comunes a las trayectorias de estos jóvenes. A lo largo de nuestro trabajo, hemos activado formas de acercar la experiencia, la memoria, la corporeidad y el discurso como posibilidades de expresión de las subjetividades singulares de estos jóvenes, que todavía son atravesados constantemente por estructuras, violencia y jerárquico.

Palabras clave: Cultura y educación; favela; juventud; universidad; extensionismo.

"Quem Sabe de Mim Sou Eu": cultural and communicative practices as pedagogical tools for vulnerable young people

\begin{abstract}
This article proposes a theoretical-methodological reflection based on the accumulated experience in the field of a university extension project that, during the last eight years, promotes activities aimed at young people in social vulnerability situations. By presenting the tools used and reflecting on the problems and challenges faced, we seek to develop a methodology that could be able to access these young people. Our goal is to explain how it is possible to use cultural practices and communication tools as a support for an emancipatory process of subjectivation, with the purpose of dismantling "self-fulfilling prophecies" common to the trajectories of these young people. Throughout our work, we have activated ways of bringing experience, memory, corporeity and speech as possibilities of expression of the unique subjectivities of these young people, who are still constantly traversed by structures, violence and hierarchy.
\end{abstract}

Keywords: Culture and education; favela; youth; university; extensionism.

\title{
"Quem Sabe de Mim Sou Eu": práticas culturais e comunicacionais como instrumentos pedagógicos junto a jovens em vulnerabilidade
}

\section{Introdução}

Propomos uma reflexão a partir da experiência acumulada no âmbito de um projeto universitário de caráter extensionista que, ao longo dos últimos oito anos, promove atividades voltadas para jovens em situação de vulnerabilidade social. Objetivamos apresentar as ferramentas usadas, questões e desafios enfrentados, bem como desenvolver um referencial teórico metodológico norteador das ações. Nossa meta é pensar como articular práticas culturais $\mathrm{e}$ ferramentas comunicacionais capazes de contribuir para um processo de 
DAEMON, Flora; MENDONÇA, Kleber; NERCOLINI, Marildo. "Quem Sabe de Mim Sou Eu": práticas culturais e comunicacionais como

instrumentos pedagógicos junto a jovens em vulnerabilidade.

PragMATIZES - Revista Latino-Americana de Estudos em Cultura,

Niterói/RJ, Ano 11, n. 20, p. 109-135, março 2021. www.periodicos.uff.br/pragmatizes - ISSN 2237-1508 (Dossiê "Tramas entre cultura e educação") subjetivação emancipador que desarme as chamadas "profecias auto realizáveis", comuns às trajetórias desses jovens.

Ao longo de nossa atuação com jovens em favelas cariocas, pudemos constatar na vivência pedagógica as dificuldades de elaborar e implementar ferramentas educacionais capazes de mobilizar e engajar tal público-alvo. Fomos nos deparando, gradualmente, com o que chamamos de armadilhas estruturais que, ao mesmo tempo, ordenam a complexa e desigual sociedade brasileira, e se atualizam no plano dos indivíduos perpetuando os processos de marginalização social e de sujeição criminal de determinados grupos.

As experiências profissional e educacional dos integrantes do projeto, bem como sua capacidades de atuação junto aos jovens, se situam na interface entre o uso de ferramentas comunicacionais e as práticas culturais locais. Dessa forma, nos dedicamos a construir uma linha de atuação que pudesse usar ferramentas diversas (a fotografia, o audiovisual, a música e os relatos pessoais memoráveis locais, por exemplo) como argumentos pedagógicos de transformação.

Assim, elaboramos uma metodologia que une reflexão teórica, observação participante e prática horizontalizada de reconhecimento e troca de saberes múltiplos. Com isso, passamos a implementar ações de capacitação destinadas à transformação, tanto dos jovens moradores de favelas cariocas, como dos estudantes universitários que participaram do projeto ao longo dos últimos oito anos. Partimos do entendimento de que para que a universidade "se pinte de negro, se pinte de mulato, não somente entre os alunos, mas também entre os professores; que se pinte de trabalhador e de campesino, que se pinte de pueblo" ${ }^{4}$, conforme defendeu Ernesto Guevara, é necessário que esta instituição se volte para esses indivíduos, não somente na condição de objetos ou interlocutores de pesquisas científicas, mas fundamentalmente como potenciais ocupantes de posições relevantes em sua estrutura.

\footnotetext{
${ }^{4}$ Trata-se de discurso proferido em 28/12/1959, no recebimento do título de doutor honoris causa na Faculdade de Pedagogia da Universidad Central de Las Villas, Cuba.
} 
DAEMON, Flora; MENDONÇA, Kleber; NERCOLINI, Marildo. "Quem Sabe de Mim Sou Eu": práticas culturais e comunicacionais como

instrumentos pedagógicos junto a jovens em vulnerabilidade.

PragMATIZES - Revista Latino-Americana de Estudos em Cultura,

Niterói/RJ, Ano 11, n. 20, p. 109-135, março 2021.
Durante o desenvolvimento do trabalho nos deparamos com a dificuldade dos jovens de vislumbrarse como parte do ensino superior público. Para além da questão concreta das barreiras de seleção baseadas em controversos critérios de acúmulo e competência, como o rendimento no ENEM, identificamos um sentimento recorrente de não pertencimento a priori àquele lugar que, embora mais próximo em função do contato com o projeto de extensão, ainda conservava distância no que se refere à ideia de fazer parte.

A vivência sistemática do projeto apontou, no entanto, para dois movimentos elementares na mudança de entendimento do papel e lugar político e simbólico - da universidade por parte dos jovens: o primeiro se refere à ideia de revelação. Para quase a totalidade dos participantes do projeto, a universidade pública se apresentava como uma abstração. Neste sentido, tomar contato com uma instituição de ensino de reconhecida relevância por meio de um projeto que sustenta práticas horizontais pode ter contribuído de maneira significativa para o desejo de desvelar um espaço que, até então, não parecia seu, por direito e por princípio.

O segundo movimento, decorrente do anterior, refere-se à introjeção do olhar do outro sobre si. Sabemos que cotidianamente esses jovens são interpelados como criminosos - concretos ou em potencial - a partir de conformação da sujeição criminal (MISSE, 2008).

entendimento deste mecanismo perverso, por parte de meninos e meninas pretos, pardos e pobres, efetiva no próprio corpo uma interdição que impossibilita postulações de ocupação de lugares com os quais não são identificados em função do caráter racista e classista da sociedade. Acreditamos que ao tomarem contato com um novo olhar sobre si, partindo de indivíduos associados ao Estado e à coisa pública - aqui materializados pela ideia de universidade, seus estudantes e professores -, sem se sentirem interpelados pelo que supostamente falta ou pela referência ao risco, esses jovens começam a se enxergar possíveis.

Uma das evidências de tal embaralhamento de lugares políticosociais é a perceptível motivação de vários jovens que faziam parte do 
DAEMON, Flora; MENDONÇA, Kleber; NERCOLINI, Marildo. "Quem Sabe de Mim Sou Eu": práticas culturais e comunicacionais como

instrumentos pedagógicos junto a jovens em vulnerabilidade.

PragMATIZES - Revista Latino-Americana de Estudos em Cultura,

Niterói/RJ, Ano 11, n. 20, p. 109-135, março 2021. projeto de extensão a se tornarem, eles também, estudantes na universidade pública. Foi dessa maneira que alguns ingressaram no ensino superior e, também, passaram a desafiar a ideia de presença do Estado nas favelas e periferias apenas como instrumento repressor das populações.

A partir de tais postulados e posturas ético-políticas o projeto Quem Sabe de Mim Sou Eu atuou, desde 2012, em favelas como Chapéu Mangueira, Babilônia, Cantagalo e Pavão-Pavãozinho, bem como em escolas públicas próximas às comunidades da zona norte do Rio de Janeiro. Decidimos, atualmente, ampliar o escopo e passar a trabalhar também junto aos jovens que cumprem medidas socioeducativas, na cidade de Niterói. Essa ação passa a ser desenvolvida no Centro de Recursos Integrados de Atendimento ao Adolescente de Niterói (CRIAAD), envolvendo parceria entre a UFF e a Prefeitura.

Quanto à equipe, o projeto contou, ao longo desses anos, com 25 bolsistas de extensão, seis bolsistas Pibic/CNPq e duas bolsistas PIBICEnsino Médio/CNPq. Alguns, inclusive, moradores de favelas. Além disso, é coordenado por três professores que são docentes de duas universidades federais e que possuem experiência nos campos da Violência, da Juventude, da Comunicação, da Música e dos Estudos de Gênero. Quem Sabe de Mim Sou Eu foi financiado por diferentes agências, tendo sido contemplado, entre outros, pelos editais PROEXT 2015 (CAPES/MEC) e Humanidades 2013, da FAPERJ. Ressalta-se, ainda, as fundamentais parcerias com iniciativas de base comunitária tais como o projeto Dá Teu Papo, a Orquestra de Percussão Mirim do Mestre Dá, o projeto de passinho desenvolvido por Key Tetra, o Núcleo de Comunicação Popular (Nucopo), além de instituições parceiras, como o CIEP 205 Frei Agostinho Fincias e alguns equipamentos culturais do Rio de Janeiro.

\section{Aspectos estruturais da} sociedade brasileira e as profecias auto realizáveis

"Favela tem história. Uma longa batalhadora história. E eu ainda espero escrever relatando o dia em que esses dois mundos forem um só, com os mesmos direitos, oportunidades e respeito. Eu não 
DAEMON, Flora; MENDONÇA, Kleber; NERCOLINI, Marildo. "Quem Sabe de Mim Sou Eu": práticas culturais e comunicacionais como

instrumentos pedagógicos junto a jovens em vulnerabilidade.

PragMATIZES - Revista Latino-Americana de Estudos em Cultura,

Niterói/RJ, Ano 11, n. 20, p. 109-135, março 2021.

terei palavras para descrever o sentimento. Mas espero um dia que pessoas como vocês enxerguem a gente."

(Thayná Rodrigues, Bolsista Pibic

Ensino Médio - Quem Sabe de Mim Sou Eu)

Uma vez que propomos uma metodologia educacional de atravessamento e de (re)construção de subjetividades no momento mesmo em que os jovens se apoderam de ferramentas da comunicação e das práticas culturais, é fundamental levar em conta dois pontos de partida que se inter-relacionam: as características específicas das localidades desses jovens e a forma desigual e violenta com a qual a sociedade brasileira historicamente se organiza.

Notamos, assim, como as potências criativas desses jovens, ainda pouco percebidas por eles mesmos e não reconhecidas socialmente, acabam sendo silenciadas por uma complexa trama de agenciamentos e de controles sociais. Tal modo de funcionamento dos aparatos estatais de administração de conflitos e de vigilância articula aspectos ligados ao estigma (GOFFMAN, 2008) atribuído a esses jovens, por meio de marcadores raciais e de classe de modo a torná-los alvos preferenciais de um complexo mecanismo de sujeição criminal (MISSE, 2008). Este processo se apresenta de maneira dissimulada a partir do estabelecimento de determinados tipos ideais que se tornam, desde sempre, "suspeitos" de condutas criminais antes mesmo da prática de qualquer ação, característica que não só justificaria como demandaria a vigilância constante por parte dos agentes do Estado. Uma combinação de invisibilidade (dos sujeitos, de seus direitos fundamentais e de suas capacidades) com uma visibilidade acionada apenas para inserir esses jovens no aparato repressor e punitivo das instituições de vigilância, punição e encarceramento (quando não das ações de extermínio).

Em cada favela onde o projeto aconteceu buscou-se sempre inserir a discussão a respeito dos saberes locais conjuntamente com $\mathrm{O}$ seu processo histórico de formação. Tal estratégia se apresenta como um antídoto ao risco de homogeneizar realidades a respeito da complexidade inerente aos diferentes sítios que compõem grandes cidades. Esta preocupação é uma forma eficiente de 
DAEMON, Flora; MENDONÇA, Kleber; NERCOLINI, Marildo. "Quem Sabe de Mim Sou Eu": práticas culturais e comunicacionais como

instrumentos pedagógicos junto a jovens em vulnerabilidade.

PragMATIZES - Revista Latino-Americana de Estudos em Cultura,

Niterói/RJ, Ano 11, n. 20, p. 109-135, março 2021.

problematizar o debate acerca da implicação juvenil, bem como de seus modos de instrumentalizar aparatos comunicacionais a favor de suas táticas e práticas culturais.

Do contrário incorreríamos no erro, bastante habitual conforme ressalta Valladares, de acreditar que ter contato com uma favela é conhecer a realidade de todas:
A favela é obrigatoriamente um morro, uma zona ocupada ilegalmente, fora da lei, um espaço subequipado, lugar de concentração dos pobres na cidade. Numa mesma denominação genérica, a palavra favela unifica situações com características muito diferentes nos planos geográfico, demográfico, urbanístico e social (VALLADARES, 2005, p. 152).

Percebe-se, assim, como instrumento fundamental de mobilização e diálogo a preocupação de levar em conta as especificidades históricas, geográficas e culturais dos diferentes lugares bem como as características singulares de seus jovens moradores. É tarefa prioritária do educador atentar para o que é diverso e múltiplo. Sem perder de vista, igualmente, o caráter agenciador de alguns padrões que acabam por se replicar, uma vez que a estrutura perversa da sociedade brasileira, por razões políticas e históricas, direciona sua máquina de moer gente (RIBEIRO, 1995) prioritariamente àqueles mesmos cidadãos postos, violentamente, à margem do processo produtivo e, portanto, em situação de vulnerabilidade socioeconômica e expostos cotidianamente à sociabilidade violenta (MACHADO SILVA, 2008).

Por conta da natureza da atuação do poder público que falhou sistematicamente em garantir o acesso a condições fundamentais de subsistência, uma das facetas da inclusão precária capitalista apenas pelo acesso a bens de consumo não essenciais, as favelas foram associadas historicamente à ideia de berço de um certo tipo de violência. Partilhamos da premissa de Misse (2008) de que a emergência de grupos de extermínio, nos anos 1950, que buscavam eliminar criminosos de baixa periculosidade, efetivou a impossibilidade de monopólio da violência pelo Estado e fez insurgir, a partir de suas ações, reações violentas que culminaram no crescimento da criminalidade, gerando 0 efeito denominado pelo sociólogo como acumulação social da violência. 
DAEMON, Flora; MENDONÇA, Kleber; NERCOLINI, Marildo. "Quem Sabe de Mim Sou Eu": práticas culturais e comunicacionais como

instrumentos pedagógicos junto a jovens em vulnerabilidade.

PragMATIZES - Revista Latino-Americana de Estudos em Cultura,

Niterói/RJ, Ano 11, n. 20, p. 109-135, março 2021. www.periodicos.uff.br/pragmatizes - ISSN 2237-1508 (Dossiê "Tramas entre cultura e educação")
Ao analisar a forma peculiar como se dá, historicamente, a administração dos conflitos no Brasil, Kant de Lima mostra como os princípios igualitários do ideal republicano esbarram em múltiplas práticas hierárquicas que no Brasil se mantém e se perpetuam em virtude de nossa herança colonial ainda presente e atuante. Neste arranjo paradoxal, a ordem pública, que

seria o resultado do conflito oriundo da oposição de interesses entre iguais, de uma sociedade igualitária, se transforma, no modelo brasileiro, numa reunião de diferentes práticas jurídicas cujo objetivo principal é manter implícitos o conflito e a estrutura desigual da sociedade (KANT DE LIMA, 1996, p. 167).

Nossa experiência no campo também identificou a recorrência do entendimento, por parte de alguns moradores, de que o sentimento de orgulho da história de resistência da favela muitas vezes se situava ao lado do discurso velado de (auto)culpabilização pelo abandono do poder público. Sinteticamente, estas falas pareciam apontar para uma assunção de certa responsabilidade pela concentração espacial da violência no chão da favela que teve início no momento de ocupação territorial dos espaços outros da cidade:

A favela ficou também registrada oficialmente como a área de habitações irregularmente construídas, sem arruamentos, sem plano urbano, sem esgotos, sem água e sem luz. Dessa precariedade urbana, resultado da pobreza de seus habitantes e do descaso do poder público, surgiram as imagens que fizeram da favela o lugar da carência, da falta, do vazio a ser preenchido pelos sentimentos humanitários, do perigo a ser erradicado pelas estratégias políticas (ZALUAR; ALVITO, 2006, p. 6)

Parece-nos central a percepção das artimanhas

capitalistas

historicamente forjadas no processo de gestão territorial das favelas. Incapaz de garantir à totalidade de seus cidadãos condições dignas, 0 Estado brasileiro inverteu esta interpretação por meio de discursos de ascensão pelo esforço individual. A consequência visível deste projeto político de cidade se materializou nas diversas gerações de jovens que encontraram nos mercados ilegais, sobretudo aquele voltado para o narcotráfico, a condição "ideal" (às vezes única) de subsistência.

Concordamos com perspectiva da Criminologia Crítica de que se o crime é parte constitutiva das sociedades, inevitavelmente este faz 
DAEMON, Flora; MENDONÇA, Kleber; NERCOLINI, Marildo. "Quem Sabe de Mim Sou Eu": práticas culturais e comunicacionais como

instrumentos pedagógicos junto a jovens em vulnerabilidade.

PragMATIZES - Revista Latino-Americana de Estudos em Cultura,

Niterói/RJ, Ano 11, n. 20, p. 109-135, março 2021.

parte de sua sociabilidade. Ainda assim, jogar luz sobre isso não significa fazer apologia ao crime, mas compreender que não há sociedade livre do delito e que definir quais ações serão tipificadas ou criminalizadas é também um gesto político. A questão que se coloca é que muitos que enveredaram pelas atividades ilegais não o fizeram num cardápio justo de oportunidades.

A história se repete pelo país: sem escola, primeiramente, e sem trabalho, num segundo momento, seguem rumo às opções mais perigosas e, por isso, proporcionalmente, mais rentáveis. O desenvolvimento desta narrativa parece evidente: ao longo de décadas, moradores das favelas assistiram a emergência, ascensão e declínio fatal de diversos jovens - seus filhos, companheiros e vizinhos -, por terem se tornado parte da cadeia do comércio ilegal de entorpecentes.

Torna-seainda mais urgente desenvolvermos metodologias pedagógicas que consigam estabelecer diálogo com essa parcela da população de modo a conseguirmos desarmar tal poderosa armadilha histórica. Nesse sentido, concordamos com Faustini de que a potência do trabalho junto à juventude é, definitivamente, transformadora, especialmente quando exercita a alteridade: "Imagine a cabeça de um jovem que sabe da sua potência, mas só encontra enquadramentos na sua frente. $\dot{E}$ um crime histórico, com raízes nas estruturas elitizadas e escravocratas da nossa cidade, mas que não pode ser naturalizado" (FAUSTINI, 2012, p. 169).

O caminho seria, então, fortalecer uma nova chave conceitual que permita "a invenção de um espaço/tempo que potencialize sobretudo a novidade - a capacidade desse jovem, considerado por muitos como inorgânico, de promover invenções de formas de se estar na vida e expressões estéticas" (ibidem). Nesse cenário, focar parte das ações utilizando ferramentas comunicacionais contemporâneas e de fácil manuseio (como o celular e os aparatos de audiovisual) cumpre, como veremos adiante, a função de articular, ao mesmo tempo, as singularidades com as quais nos deparamos e as possibilidades de práticas culturais específicas que 
DAEMON, Flora; MENDONÇA, Kleber; NERCOLINI, Marildo. "Quem Sabe de Mim Sou Eu": práticas culturais e comunicacionais como

instrumentos pedagógicos junto a jovens em vulnerabilidade.

PragMATIZES - Revista Latino-Americana de Estudos em Cultura,

Niterói/RJ, Ano 11, n. 20, p. 109-135, março 2021. www.periodicos.uff.br/pragmatizes - ISSN 2237-1508 (Dossiê "Tramas entre cultura e educação") serão tematizadas pelos jovens em suas produções.

É evidente o peso dos processos históricos que fazem a manutenção da exclusão de pobres neste país e que limitam as possibilidades de agência dos sujeitos focalizados em nossas ações. Ainda assim, nos alinhamos com a perspectiva de Enne e Passos que defendem ser importante considerarmos que

as estruturas são estruturantes, mas também estruturadas, não perdendo de vista o papel de sujeitos ativos, agentes sociais, dessas múltiplas juventudes. Entendemos que mesmo diante de campos de possibilidades diferenciados, sujeitos projetam e constroem realidades, disputando sentidos, se reapropriando e ressignificando o mundo. Mas, para além das idiossincrasias das subjetividades, compreendemos que estruturas sociais diferenciadas vão requerer estratégias e táticas também múltiplas para que essas várias juventudes agenciem e se coloquem como sujeitos de suas realidades (ENNE; PASSOS, 2018, p. 130).

É justamente por entendermos os jovens como sujeitos das próprias narrativas e trajetórias, passíveis de autorreflexão e dotados de capacidade de agência e mobilidade, que desenvolvemos as ações do projeto. Foi possível perceber vários momentos nos quais rompeu-se o ciclo perverso que acomete jovens em posição de vulnerabilidade que, por sua vez, poderiam se tornar vetores da sociabilidade violenta como uma profecia autorrealizável (SOARES; BILL; ATHAYDE, 2005).

Uma das condições prioritárias para o sucesso dessa empreitada, que mereceu um olhar teórico mais detido de nossa parte, foi justamente problematizar lugares de poder que atravessam, institucional e subjetivamente, a forma como os saberes agenciam professores e hierarquizam sujeitos e possibilidades de existência.

\section{Embaralhando hierarquias: a} importância de descentrar o olhar

Foucault, ao mapear o funcionamento das instituições disciplinares e os modos como os discursos se organizam, aponta como as formas de saber, historicamente produzidas, engendram estruturas hierárquicas de poder (FOUCAULT, 1987). Assim, os grupos que ocupam o lugar daqueles que detém saber sobre outrem autorizam-se a exercer sobre seus objetos do conhecimento relações de dominação e controle. 
DAEMON, Flora; MENDONÇA, Kleber; NERCOLINI, Marildo. "Quem Sabe de Mim Sou Eu": práticas culturais e comunicacionais como

instrumentos pedagógicos junto a jovens em vulnerabilidade.

PragMATIZES - Revista Latino-Americana de Estudos em Cultura,

Niterói/RJ, Ano 11, n. 20, p. 109-135, março 2021. www.periodicos.uff.br/pragmatizes - ISSN 2237-1508 (Dossiê "Tramas entre cultura e educação")
Aspectos dos agenciamentos presentes na articulação entre saber e poder se reproduzem, muitas vezes, no funcionamento cotidiano das instituições de ensino, em seus diferentes níveis. Não raro, de modo mais ou menos inconsciente, tais relações hierárquicas acabam norteando e se atualizando, mesmo em práticas pedagógicas que buscam, de forma bem intencionada, intervenções empoderadoras junto aos jovens atendidos.

Uma reflexão que pode ajudar a explicitar essas matrizes hierárquicas do pensamento e das práticas de ensino e aprendizado é desenvolvida por Doreen Massey (2008). A autora propõe uma relação entre geografia, política e estratégias de legitimação dos saberes para pensar criticamente a proliferação mundial de tecnopolos universitários (Science Parks) nos moldes do Vale do Silício. A geógrafa defende que tais espaços de conhecimento atualizam historicidades porque "articulam, de forma física, tanto a espacialidade social da produção do conhecimento quanto uma espacialidade imaginada da relação do conhecimento" (MASSEY, 2008, p. 209). Nos tecnopólos há uma atualização de três trajetórias do pensamento hegemônico ocidental que dizem respeito aos modos como a ciência e a educação são pensadas hoje, quem pode praticá-la e quais os saberes "legítimos" em nossa sociedade.

A primeira trajetória materializa uma ciência que se instaura pela divisão e pela distância geográfica, na medida em que as universidade se organizam em amplos espaços confinados à margem das cidades (ou, quando próximas, geograficamente, ainda assim alijadas da vida cotidiana local). Uma atualização contemporânea da fuga monástica medieval para 0 deserto como condição de buscar e manter o conhecimento.

É a recapitulação de uma velha estória da história ocidental: a reclusão espacial do deserto para os primeiros pensadores cristãos, o surgimento de mosteiros como lugares de elite e produção de conhecimento, as universidades medievais. Todos eles lugares que cristalizaram, através da espacialização, uma separação entre mente e corpo. (MASSEY, 2008, p. 207)

Esse saber como produto do afastamento do mundo se desdobra na cesura entre sujeito conhecedor $\mathrm{e}$ objeto do conhecimento, não por 
DAEMON, Flora; MENDONÇA, Kleber; NERCOLINI, Marildo. "Quem Sabe de Mim Sou Eu": práticas culturais e comunicacionais como

instrumentos pedagógicos junto a jovens em vulnerabilidade.

PragMATIZES - Revista Latino-Americana de Estudos em Cultura,

Niterói/RJ, Ano 11, n. 20, p. 109-135, março 2021.

acaso o mesmo solo onde Foucault viu florescer relações hierárquicas de saber/poder. Além da objetividade como paradigma, tal fuga estabelece ainda outra paisagem na geografia do saber: a distância dos homens em relação às mulheres. A hegemonia masculina nos lugares de saber é "resultado de uma história mais longa e mais profunda da construção do gênero que, ela própria foi/é incluída espacialmente na construção de "lugares de conhecimento" defensivos, especializados" (ibid., p. 208). Consolida-se uma gestão da produção de conhecimento calcada não só nas oposições sujeito/objeto e vida cotidiana/isolamento reflexivo, mas também na naturalização da hierarquia entre "legítimos" pensadores fundada em uma distinção (discriminação) histórica de gênero: pensar não seria, evidentemente, "coisa de mulher".

Há uma última trajetória nas instituições de saber contemporâneas: a questão de classe: "esses lugares de produção de conhecimento são, também, lugares de elite, da produção de conhecimento legítimo, reconhecido, autorizado" (ibidem). Tal costura de objetividade distanciada, masculinidade do pensamento e legitimação dos saberes sedimenta um amplo silenciamento de outras possibilidades de conhecimento e práticas. Tais formas outras, mesmo situadas "para além dos muros", são constantemente aprimoradas, repartidas e multiplicadas por parcelas importantes e heterogêneas da população.

Defendemos ser impossível estabelecer atuações de fato efetivas junto a jovens moradores de favelas que não sejam capazes de colocar em diálogo os saberes universitários quase sempre impregnados dessa tripla relação de poder e distinção - , com a sabedoria local, polifônica, sedimentada e constantemente atualizada por práticas culturais e trocas cotidianas muitas vezes silenciada como as formas de conhecimento que são.

Reside igualmente na proposta de desarmar as armadilhas de classe, raça e gênero dessa geografia do conhecimento o esforço pedagógico proposto por bell hooks ${ }^{5}$ (2013), em diálogo com Paulo Freire, na defesa de uma educação para a liberdade. Um dos desafios pedagógicos

\footnotetext{
${ }^{5}$ Nota do editor: a grafia em letras minúsculas é escolha da própria autora.
} 
DAEMON, Flora; MENDONÇA, Kleber; NERCOLINI, Marildo. "Quem Sabe de Mim Sou Eu": práticas culturais e comunicacionais como

instrumentos pedagógicos junto a jovens em vulnerabilidade.

PragMATIZES - Revista Latino-Americana de Estudos em Cultura,

Niterói/RJ, Ano 11, n. 20, p. 109-135, março 2021. enfrentados em nossa atuação foi justamente criar condições de colocar em diálogo saberes diversos (locais e universitários) ao mesmo tempo em que desconstruíamos, pela prática crítica coletiva, o que hooks define como "voz privilegiada da autoridade". Ela defende que uma das possibilidades mais potentes de atuação é abrir espaços para que a experiência se converta em elemento facilitador dos processos ativos de ensino e aprendizagem:

\begin{abstract}
o ato de ouvir coletivamente uns aos outros afirma o valor e a unicidade de cada voz. Esse exercício ressalta a experiência sem privilegiar as vozes dos alunos de um grupo qualquer. Ajuda a criar uma consciência comunitária da diversidade de nossas experiências e proporciona uma certa noção daquelas experiências que podem informar o modo como pensamos e que dizemos. (...) Esse exercício transforma a sala de aula num espaço onde a experiência é valorizada, não negada nem considerada sem significado (HOOKS, 2013, p. 114-115).
\end{abstract}

A eficácia da incorporação da experiência como ferramenta de atuação pedagógica, capaz de horizontalizar as relações nas ações extensionistas, ficou evidenciada em diversos momentos ao longo desses oito anos do projeto. Podemos destacar dois aspectos fundamentais: os espaços de troca e de conversa e os acionamentos memoráveis por parte dos integrantes. estabelecimento de rodas de debate, mais do que momentos de catarse ou relaxamento, permitem a todas as pessoas em contato naquela ação (estudantes universitários, professores e jovens moradores de favelas) a explicitação de singularidades no mesmo gesto em que pressupõe o contato com diferentes formas de conhecimento, possibilidades-outras de trajetórias pessoais e modos singulares de compartilhamento $\mathrm{e}$ reconhecimento de saberes.

Já as atividades que demandavam $\circ$ acionamento da memória (individual e coletiva) faziam emergir a interface entre as vivências pessoais de cada um dos jovens e os acontecimentos históricos importantes para a localidade. Em uma das ações, por exemplo, uma capacitação em audiovisual propunha que os jovens se dividissem em grupos que teriam a função de caminhar pela favela e buscar ouvir pessoas mais velhas consideradas importantes nas suas localidades. O objetivo era ouvir de algumas seus saberes específicos que desejassem compartilhar e, em outra 
DAEMON, Flora; MENDONÇA, Kleber; NERCOLINI, Marildo. "Quem Sabe de Mim Sou Eu": práticas culturais e comunicacionais como

instrumentos pedagógicos junto a jovens em vulnerabilidade.

PragMATIZES - Revista Latino-Americana de Estudos em Cultura,

Niterói/RJ, Ano 11, n. 20, p. 109-135, março 2021.

frente, recolher relatos sobre acontecimentos memoráveis da favela que atribuíssem sentidos coletivos aos diferentes sítios que constituem sua região. Assim, mais do que meramente ensinar os jovens a filmar e a gravar registros para um documentário, o objetivo era percebermos, todos, como cada comunidade se constitui de uma riqueza e pluralidade de vivências, lugares, gestos, pessoas, conflitos, contradições, memórias e trajetórias, bem como promover o exercício de uma escuta qualificada.

Esse exemplo de atividade evidencia como articulamos os pilares teórico-pedagógico acionados de modo prático ao longo da atuação extensionista. É por essa razão que o objetivo principal da metodologia, centrada na interface entre ações culturais locais e uso de ferramentas comunicacionais, não é o resultado artístico final dos conteúdos. Queremos, isso sim, acionar modos potentes de trazer para o plano do visível a experiência, a memória, a corporalidade e a fala como possibilidades de expressão das subjetividades singulares desses jovens, ainda assim constantemente

\section{Pilares teóricos e análise do funcionamento da metodologia de atuação}

Um caso emblemático da complexidade envolvida na atuação junto a jovens moradores de favelas foi vivenciado pelos integrantes do projeto em uma ação ocorrida no ano de 2014. Estávamos, então, realizando uma série de registros em vídeo com 
alguns adolescentes dos Morros do Cantagalo e Pavão Pavãozinho que fariam relatos sobre as visitas guiadas que aconteceram em diferentes centros culturais do município do Rio de Janeiro. A ideia era construir uma memória sobre tais ações, bem como refletir sobre os modos de apropriação de tais equipamentos de cultura por sujeitos que, até então, não haviam tido experiência similar.

Neste sentido, nos direcionamos ao Instituto de Arte e Comunicação da UFF juntamente com quatro jovens da referida favela. Coincidentemente, acontecia naquele momento um evento organizado por alunos. Ao ingressarmos no ambiente nos deparamos com um show de uma banda de rock estudantil, o que mobilizou a atenção dos participantes do projeto e postergou nossa entrada no estúdio. Percebendo um vislumbre de encantamento diante da cena festiva, um dos coordenadores do projeto perguntou sobre 0 que estavam achando da experiência inédita de estar nas dependências de uma universidade. A resposta de uma das integrantes surpreendeu: "Tô amando. Parece que eu estou dentro de um episódio de Glee ${ }^{6 "}$.

Após o susto inicial diante da associação da experiência universitária com uma série estadunidense, considerada inusitada pelo professor que havia feito a pergunta (em parte por seu desconhecimento a respeito do que tratava a referida produção audiovisual), fomos apresentados a uma rica complexidade que, evidentemente, compunha a subjetividade daquela jovem. A resposta explicitava, de certa forma, aquilo que Martin-Barbero (1997) define como "competência comunicacional". Percebemos uma geração de jovens moradores das favelas das grandes cidades plenamente capazes de reconhecer, assimilar e negociar os códigos compartilhados e veiculados por uma cultura de massa global.

Estávamos diante de uma jovem que, em sua localidade de residência, exercia a função de mediar

\footnotetext{
${ }^{6}$ Trata-se de uma série musical americana na qual estudantes de ensino médio vivem suas peripécias e dão os primeiros passos artísticos, especialmente ligados à dança e à música, o que explica a associação feita pela adolescente. No momento da pergunta, a banda tocava uma música de Lady Gaga.
} 
as instruções do professor de uma orquestra de percussão mirim e que, simultaneamente, consumia, entre outros conteúdos, a série que descrevia as agruras e peripécias de jovens estudantes americanos de sua idade. Em resumo, o momento de surpresa ofereceu uma oportunidade de aprendizado, também para os integrantes do projeto: derrubar por terra eventuais resquícios que ainda existissem do equívoco iluminista de considerar o fato de trazer os jovens "excluídos" para a Universidade como um gesto que apresenta 0 esclarecimento e o lugar do saber a alguém desprovido de recursos simbólicos.

Ficava evidente de que forma tal visão simplista não dava conta da complexidade desses sujeitos. É um fato que esses jovens são atravessados pela falta, fruto da inclusão precária num processo de consumo que regala a muitos o papel do extermínio, da sujeição criminal ou de permanecer à margem das possibilidades de formação educacional de qualidade. A breve resposta, no entanto, também jogava luz a subjetividades que praticam a cidade em seus mais diversos espaços, que consomem e se identificam com conteúdos globais de comunicação de massa e que negociam esses sentidos veiculados com suas práticas cotidianas, igualmente em diálogo com uma miríades de informações e estímulos.

O episódio ensinava para os integrantes do projeto como as negociações entre tais jovens e os saberes acadêmicos poderia assumir aspectos mais ricos e contraditórios do que simples modos de esclarecimento e apresentação a eles dos lugares de erudição. Assim, competência comunicacional associada aos gestos identitários estabelecidos a partir de práticas culturais locais se articulam e se entrelaçam naqueles jovens. Cabia, então, ao projeto, estimular essas potências já em funcionamento e acrescentar, nessa mistura, elementos dos saberes universitários que estavam, por sua vez, sendo também afetados pelos curtos circuitos que esses (des)encontros passaram a acionar.

Após essa conversa, fomos para o estúdio de gravação apresentar as técnicas de registro e de edição utilizadas por profissionais de comunicação. Após a entrada no 
espaço de saber ter sido "suavizada" por práticas culturais negociáveis simbolicamente pelos jovens, o contato com o conhecimento formal se realizou de forma mais potente. Sabemos, todos, como estar diante do saber institucionalizado pode ser violento e excludente.

O episódio ilustra bem, portanto, os três eixos que dão sustentação à metodologia aqui proposta e que se entrelaçam: a) articulação, nos jovens, da noção de projeto e de construção de futuro; b) de modo a deslocar o entendimento de suas localidades do lugar prioritário da violência na cidade para um lugar legítimo de saber; c) no qual se desenvolvem práticas culturais que podem se tornar instrumentos potentes, especialmente quando postos em diálogo com práticas comunicacionais resultando na produção de conteúdos informativos e artísticos.

Estimulamos, em síntese, um processo de capacitação técnica e transformação de suas subjetividades ao mesmo tempo em que nos alimentamos da convergência entre os conteúdos já consumidos pelos jovens e as práticas culturais às quais têm acesso prévio.

\subsection{Das profecias que se autocumprem aos projetos de futuros-outros}

A constatação da importância de um dos principais pilares norteadores de nossas ações se deu ao longo dos primeiros anos de atuação junto aos jovens. Era comum, ao propormos exercícios de reflexão sobre si e de questionamentos a respeito do futuro, a ausência nas falas e nas práticas desses jovens da noção de projeto. A temporalidade dos discursos sustentados nas rodas de conversa, bem como nos exercícios propostos, tendia a congelar-se no agora e, quando muito, em eventuais rememorações pontuais de momentos marcantes das trajetórias individuais. O futuro era uma ausência tão incômoda, para nós, como constante nos relatos.

Sabe-se que a construção da identidade pressupõe a articulação entre presente, passado e futuro, em um jogo interconectado de resgate e articulação de vivências e aprendizados já vividos ou adquiridos, feitos no presente, tendo em vista a 
DAEMON, Flora; MENDONÇA, Kleber; NERCOLINI, Marildo. "Quem Sabe de Mim Sou Eu": práticas culturais e comunicacionais como

instrumentos pedagógicos junto a jovens em vulnerabilidade.

PragMATIZES - Revista Latino-Americana de Estudos em Cultura,

Niterói/RJ, Ano 11, n. 20, p. 109-135, março 2021.

elaboração de projetos de vida para o futuro. As temporalidades, portanto, enredam-se de forma a darem uma certa conformação identitária, sempre sujeita a novos rearranjos.

Resgatando Gilberto Velho (1994), e dialogando também com Pollak (1992) e Halbwachs (1990), passamos a ressaltar e aprofundar junto a esses jovens esse processo de construção do eu, da própria identidade. Se, por um lado, o resgate da memória permite uma visão retrospectiva, criando uma narrativa de si que seleciona, ordena e dá coerência à trajetória pessoal, ela, em continuação, precisa vir articulada com a ideia de PROJETO, isto é, o exercício de antecipar o futuro, organizar os meios necessários para atingir os fins. Se essa dimensão projetual não existe, a construção identitária se fragiliza, pois o sujeito não consegue estabelecer uma linha de continuidade que dá sentido ao seu agir no presente.

Defendemos, então, o uso constante de elementos pedagógicos que estimulem os processos de autorreflexão de modo a fomentar a análise da própria trajetória de vida por meio da atenção às dimensões de presente, passado e futuro, sempre em relação causal. Aos poucos, a combinação entre a auto-reflexão e as atividades culturais e comunicacionais vão permitindo, nos jovens, o surgimento cada vez mais evidente de planos e desejos de transformação de si, além da construção de futurosoutros que não apenas a mera reprodução dos lugares sociais apresentados, até então, como únicos para aqueles jovens.

Antes, porém, de apresentar concretamente a universidade como um desses sítios de futuros-outros possíveis, trabalhamos ações que promovem a releitura das suas próprias localidades como igualmente potentes e não apenas sítio onde residiria a carência e a falta (material, de horizontes e de perspectivas).

\section{2 $\mathrm{Da}$ dor da perda à potência dos saberes locais}

Vimos de que forma uma centralidade colonialista e ocidental organizou, historicamente, um duplo processo que permitia a legitimação de determinadas formas de conhecimento, no mesmo movimento em que silenciava outras possibilidades de saber, especialmente aqueles 
DAEMON, Flora; MENDONÇA, Kleber; NERCOLINI, Marildo. "Quem Sabe de Mim Sou Eu": práticas culturais e comunicacionais como

instrumentos pedagógicos junto a jovens em vulnerabilidade.

PragMATIZES - Revista Latino-Americana de Estudos em Cultura,

Niterói/RJ, Ano 11, n. 20, p. 109-135, março 2021.

cotidianos

e locais.

Um

desdobramento, às vezes involuntário, de tal gesto de enquadramento pode ser percebido na eventual dificuldade de algumas rotinas pedagógicas de incorporar, como elementos centrais, aspectos da vida cotidiana dos jovens moradores de favela. Percebemos que dialogar de modo mais aberto com as ferramentas habituais dos jovens, como o uso ativo do celular e das redes sociais, suas danças e manifestações musicais e poéticas (como o rap, o funk e o hip hop), facilita 0 acesso às diferentes propostas de aprendizagem sugeridas nas nossas atividades.

Ao relacionar os processos de letramento no Brasil com a luta dos sujeitos pelo direito de construir espaços de significação (e de vida), Orlandi lança um olhar sobre as estratégias desenvolvidas por pichadores e grafiteiros nos muros das cidades. Para além do debate sobre criminalização da prática e levando em conta a dificuldade de acesso aos bancos das escolas, esses jovens "têm, no muro recém pintado, a página em branco onde inscrever-se simbolicamente, onde escrever" (ORLANDI, 2004, p. 107).
Trata-se de uma grafia urbana que muitas vezes se converte em rara possibilidade para determinados sujeitos, ao elaborarem conteúdos próprios, estabelecerem processos de comunicação, protagonismo e reconhecimento com seus pares. Diante da emergência desses traços compartilhados, produz-se, ainda, uma (re)significação dos espaços locais a partir do olhar dos próprios moradores. Nesse sentido, nossa proposta de metodologia busca estimular, nos jovens, o mesmo gesto autoral de potencializar as capacidades de inscrição de si na vida da cidade.

Um exemplo dessa potência pôde ser visto durante uma caminhada no Cantagalo e Pavão-Pavãozinho. Poucos dias antes, o dançarino Douglas Rafael da Silva Pereira, o DG, morador e cuja carreira já havia transcendido os limites da favela, havia sido assassinado durante uma ação policial. Ao passarem por um grafite recém pintado por Acme, um artista local consagrado no Brasil, participantes do projeto silenciaram para contemplar. Em seguida começaram a entoar, quase em uníssono, os versos de um funk composto por outro artista local, MC 
DAEMON, Flora; MENDONÇA, Kleber; NERCOLINI, Marildo. "Quem Sabe de Mim Sou Eu": práticas culturais e comunicacionais como

instrumentos pedagógicos junto a jovens em vulnerabilidade.

PragMATIZES - Revista Latino-Americana de Estudos em Cultura,

Niterói/RJ, Ano 11, n. 20, p. 109-135, março 2021.

Cabelinho, em homenagem ao DG.

Ficou claro para os bolsistas do projeto que aquela ferida, ainda aberta, estava sendo elaborada por meio da arte nos muros e das palavras incorporadas aos demais sons da favela.

\subsection{Comunicação e Cultura como elementos da prática pedagógica}

Vimos como estamos diante de jovens que convivem, cotidianamente, com ferramentas de comunicação e delas fazem uso para se conectar e se expressar, inclusive artisticamente. Nesse sentido, o gesto de utilizar recursos audiovisuais e comunicacionais nas ações têm um caráter meio e não fim. O ensino das técnicas de registro e compartilhamento de conteúdos artísticos e comunicacionais, bem como as visitas aos laboratórios e demais espaços da Universidade, buscam mais a transformação das subjetividades do que a excelência artística.

Tal opção se justifica ao acionarmos os usos contemporâneos da artes, incluindo as de origem periférica, como instrumentos de sociabilidade. Entendemos a cultura como campo de embate a partir do qual práticas, valores e significados (do mundo e de si mesmo) se (re)constroem de modo dinâmico a partir de relações de forças, sempre desiguais (WILLIAMS, 2011). Trata-se do terreno privilegiado no qual os sujeitos buscam narrar-se e narrar o espaço em que vivem, contribuindo assim para a criação de memória e identidade sociais, cujas teias de significados estão constantemente em disputa (GEERTZ, 1989).

Ao entendermos 0 território como espaço construído históricosocialmente, o que implica tanto uma apropriação simbólica/cultural (em seu sentido mais imaterial), quanto um "domínio" político/econômico (com traços mais propriamente materiais), trabalhamos a dimensão das práticas culturais de modo a contribuir para transformação individual a partir de estímulos diversos. Norteamos, assim, tanto a oferta de oficinas como a busca da ampliação de referências dos jovens, sem perder de vista o estímulo à expressão.

Tal junção entre saberes e práticas culturais locais e modos de produção de territorialidades específicas, bem como os demais pilares que fundamentam nossa metodologia de atuação foram 
DAEMON, Flora; MENDONÇA, Kleber; NERCOLINI, Marildo. "Quem Sabe de Mim Sou Eu": práticas culturais e comunicacionais como

instrumentos pedagógicos junto a jovens em vulnerabilidade.

PragMATIZES - Revista Latino-Americana de Estudos em Cultura,

Niterói/RJ, Ano 11, n. 20, p. 109-135, março 2021.

observados de modo bastante evidente em uma atividade realizada junto com os jovens nas dependências da universidade.

\section{5. "Hoje o Cantagalo é aqui": corpos} e práticas que deslocam sentidos e mobilizam saberes

Nas etapas anteriores apresentamos um percurso teóricometodológico a partir do qual foram idealizadas as ações do projeto de extensão. Cabe, agora, refletir sobre uma série de atividades desenvolvidas no âmbito da ação intitulada como "Hoje o Cantagalo é Aqui", em referência ao nome da favela de onde partiram os jovens músicos da Orquestra Mirim de Percussão do Mestre Dá e os dançarinos de passinho, e ao movimento de ocupação das dependências da UFF, em setembro de 2014.

Durante dois dias, o Instituto de Arte e Comunicação se tornou, conforme as palavras do Mestre Dá, "um pedacinho da favela". Essa fala, embora poética, poderia apresentar contradições reveladoras justamente do que o projeto de extensão não gostaria de ser. O pressuposto de nosso trabalho parte da ideia de que

tanto os polos distintivos, quanto os muros invisíveis, precisam ser evidenciados para que seja possível promover uma intervenção efetiva nas perversas inclusões precárias de pretos, pobres e periféricos. Para tanto, não bastava ser um "pedaço" da favela ou um dia em sua referência. Era necessário que nossa atuação incluísse a consciência de seus limites, tanto quanto o desejo de gerar afetações profundas em todos os presentes, de modo a implicá-los num projeto de transformação da própria ideia de universidade.

Dessa forma, para pensar a presença de jovens oriundos da favela na qualidade de corpos da exceção num campus universitário, a equipe do projeto debateu intensamente sobre o lugar que essas pessoas teriam durante a ação. O cuidado era, justamente, não resvalar numa exotização de tais figuras ou em contatos objetificados. Assim, chegamos à conclusão de que o princípio norteador das ações deveria ser a reafirmação do caráter pedagógico da universidade. Desta vez, com a contribuição de sujeitos que, não raro, são observados a partir do viés da desconfiança. Dito de outra 
DAEMON, Flora; MENDONÇA, Kleber; NERCOLINI, Marildo. "Quem Sabe de Mim Sou Eu": práticas culturais e comunicacionais como

instrumentos pedagógicos junto a jovens em vulnerabilidade.

PragMATIZES - Revista Latino-Americana de Estudos em Cultura,

Niterói/RJ, Ano 11, n. 20, p. 109-135, março 2021.

forma, determinamos que a presença dos jovens deveria reafirmar, precisamente, seu lugar e capacidade de promover saberes.

Foi dessa maneira que foram desenhadas três atividades complementares em que moradores das favelas figuravam na posição de educadores junto ao corpo discente, docente e administrativo da UFF. A primeira era uma oficina de percussão com cerca 25 jovens que ensinaram o manuseio dos instrumentos, as diferenças entre ritmos e sonoridades e, principalmente, demonstraram ao público presente formas diversas de ocupar o espaço "canônico" do saber, entremeando o som seco do surdo, a estridência do tamborim, com histórias das favelas e movimentos de quadril.

$\mathrm{Na}$ segunda atividade, uma oficina de passinho, percebemos que os limites espaciais originalmente estabelecidos para concentrar o olhar do público e, assim, forjar um palco, eram, na verdade, restritivos da potência daquela ação. Em poucos minutos, jovens de idades diversas, oriundos de favelas, tomando posse de seus lugares de professores, quebraram o protocolo idealizado, e passaram a orientar os participantes a transitar por todo campus fazendo o uso de seus corpos a partir de movimentos atípicos ao local. A cena, emblemática, revelava mais do que eventuais dificuldades de mover os pés com destreza e graça ao som do funk. Ela demonstrava aos presentes que todos os corpos que habitam cotidiana ou excepcionalmente - a universidade são inevitavelmente políticos e por isso, passíveis de reflexão a seu respeito e, fundamentalmente, inclusão efetiva.

Ainda no esteio das revelações proporcionadas pela oficina de passinho, a equipe se deparou com um acontecimento desestabilizador. Num dado momento, olhar para o IACS-UFF era visualizar a possibilidade de quebra de rígidas estruturas que historicamente instituíram valorações e exclusões diversas. Os corpos dedicados à seriedade no ensaio dos movimentos e a batida do funk instigaram, também, o olhar de dois meninos negros que passavam pela rua. Possíveis moradores da favela vizinha, as crianças permaneceram interessadas por tudo o que era aquela universidade que elas até então não enxergavam. Embora próxima e corriqueira, a UFF 
DAEMON, Flora; MENDONÇA, Kleber; NERCOLINI, Marildo. "Quem Sabe de Mim Sou Eu": práticas culturais e comunicacionais como

instrumentos pedagógicos junto a jovens em vulnerabilidade.

PragMATIZES - Revista Latino-Americana de Estudos em Cultura,

Niterói/RJ, Ano 11, n. 20, p. 109-135, março 2021.

dos muros invisíveis e eficientes, se tornara um espaço possível para aqueles corpos. Ainda assim, diante do convite de um dos coordenadores do projeto, os meninos titubeantes, declinaram do gesto político de permanecer. Talvez por saberem, com algum grau de consciência possível a crianças, que aquilo se tratava de uma exceção.

A última atividade era uma mesa intitulada como "O fazer cultural na favela, saber midiático e protagonismo social". Sua composição contou com Anderson José Ribeiro, do projeto Dá Teu Papo, Beatriz Pimentel, produtora cultural, Eduardo Baptista, da Maneh Produções, Key Tetra, coreógrafo de passinho e produtor cultural, além dos coordenadores do projeto.

O debate girou em torno da politização daquelas presenças externas à UFF. Num dado momento, uma aluna que estava na plateia apresentou sua história, na qualidade de mulher negra e moradora de favela, e falou da importância da constituição de reflexões e práticas que partam da favela para pensar a universidade e não o contrário. Tal provocação se alinha com o que norteia o projeto
Quem Sabe de Mim Sou Eu. Não à toa, esse nome permanece como uma diretriz no estabelecimento dos princípios de nossa atuação, assim como lembrete das armadilhas de tutela e exotização das quais buscamos desviar.

\section{Conclusões (provisórias)}

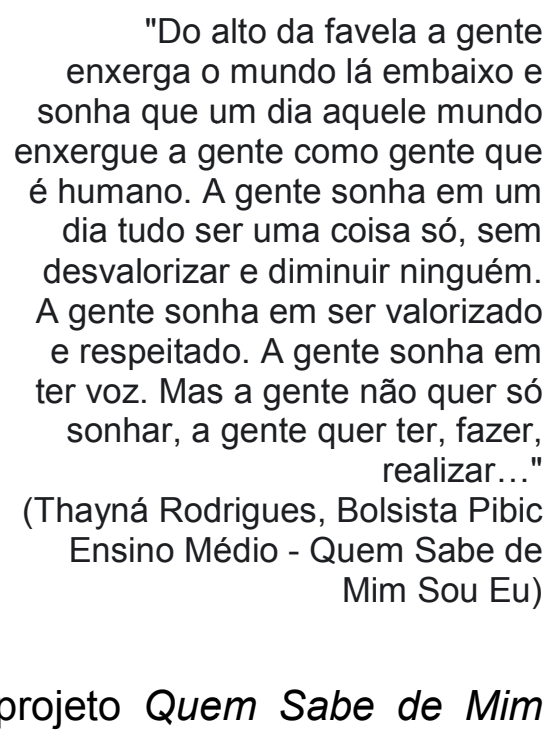
Sou completou oito anos. Ao longo dessa trajetória ainda em curso, acumulamos histórias felizes, equívocos e, principalmente, o desejo de colocarmo-nos disponíveis para rever 0 que fosse necessário. Trabalhar com gente demanda um esforço contínuo de não acomodação, capacidade inventiva e, sobretudo, de se perceber como sujeito relacional.

Foi dessa forma, inclusive, que nos deparamos com um dos episódios 
DAEMON, Flora; MENDONÇA, Kleber; NERCOLINI, Marildo. "Quem Sabe de Mim Sou Eu": práticas culturais e comunicacionais como

instrumentos pedagógicos junto a jovens em vulnerabilidade.

PragMATIZES - Revista Latino-Americana de Estudos em Cultura

Niterói/RJ, Ano 11, n. 20, p. 109-135, março 2021.

mais marcantes de nossa caminhada.

Durante anos tivemos como parceiro um rapaz morador da Babilônia.

Sempre implicado com questões de cunho social, mobilizador de atividades comunitárias, ele se apresentava como uma liderança, especialmente para os mais jovens. O início dessa relação, porém, não foi simples justamente porque ele nos enxergava como o Estado, com o qual estava acostumado a lidar, que ora rompia as portas das casas da favela sem licença ou respeito, ora se aproximava para usá-los enquanto objetos e não tratá-los como interlocutores.

Acreditamos que a forma que escolhemos para entrar, permanecer e nos relacionar nas favelas foi determinante para que esse olhar de desconfiança se desvanecesse a partir das interações implicadas. Com respeito às temporalidades de todos, os vínculos se fortaleciam, as relações se embaralhavam e geravam impactos até então inéditos. Foi dessa maneira que recebemos as palavras do tal rapaz, liderança da Babilônia, com um misto de surpresa e alegria. Ele nos procurou para dizer que sua visão sobre o que era a universidade havia mudado em função do que nós

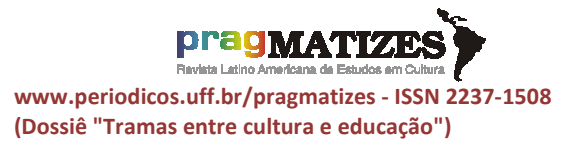

(Dossiê "Tramas entre cultura e educação")

apresentamos para ele. Ainda que soubesse que, de alguma maneira, não éramos a regra da instituição, mostrávamos o que ela poderia ser, sobretudo se mais pessoas como ele tivessem condições de transformá-la.

Disse-nos, ainda, que passou a se pensar possível no ensino superior porque viu, em nossos olhos, que o enxergávamos dessa maneira. $E$ foi assim que resolveu voltar a estudar, finalizou os estudos referentes ao ensino médio num supletivo e se inscreveu no ENEM. Conseguiu, na segunda tentativa, uma vaga no curso de Pedagogia na UFF. O contato com Paulo Freire, sobretudo com o livro Pedagogia da Autonomia, impactou profundamente nessa decisão.

Valladares desenvolveu uma pesquisa sobre mobilidade social de moradores de favelas por meio do ingresso ao ensino superior. A socióloga, identificou a ênfase recorrente no "ser alguém" e "ser diferente dos outros" como agente motivador. "Lembremo-nos de que, no Brasil, obter um diploma universitário é indicador de ascensão social. (...). Ser detentor de um título universitário permitiria, assim, a alguns moradores de favelas, sobressair em meio a uma 
DAEMON, Flora; MENDONÇA, Kleber; NERCOLINI, Marildo. "Quem Sabe de Mim Sou Eu": práticas culturais e comunicacionais como

instrumentos pedagógicos junto a jovens em vulnerabilidade.

PragMATIZES - Revista Latino-Americana de Estudos em Cultura,

Niterói/RJ, Ano 11, n. 20, p. 109-135, março 2021.

multidão de 'iguais'” (VALLADARES, 2010, p. 168).

Essa tendência distintiva se choca, justamente, com o olhar desse jovem universitário, morador da Babilônia, para si. Comumente celebrado na favela como alguém que "chegou lá" por ter ingressado no ensino superior público ele repete, como uma espécie de mantra politizado, que ele não é a exceção da favela, mas a regra. Tal posição, embora quantitativamente contraditória no que diz respeito à ainda minoritária presença de pretos e pobres nos bancos universitários, reitera justamente o que mobiliza e justifica nossa atuação no sentido de fomentar o desejo de transformação.

O rapaz, antes parceiro por ser um morador mobilizado da favela é, atualmente, integrante do projeto de extensão na qualidade de aluno da UFF. Ele continua sendo uma liderança comunitária, pai e mototaxista. Não raro é possível encontrá-lo, no intervalo de seu trabalho de translado, lendo um livro ou equilibrando páginas xerocadas dos conteúdos das aulas. A vida dele é, atualmente, mais complexa do que era antes. Mas ele se tornou alguém que

O corvo, insatisfeito com sua condição, admirava à distância a comunidade dos pombos - marcada pela elegância, pela cultura e pela beleza. Até que, certo dia, toma uma posição radical: pega uma lata de tinta branca e pinta-se inteiramente. Com essa nova roupagem, dirige-se ao pombal; lá chegando, é rapidamente identificado pelos pombos originais, que não permitem seu ingresso na sociedade. Decepcionado, decide voltar ao convívio dos seus pares - os corvos. Lá chegando, todavia, a decepção se faz mais profunda: seus antigos irmãos não o reconhecem e repudiam. Assim, sem ter o que tinha e não alcançando o que desejava, ficou o pobre corvo só, lamentando sua singular condição. (SOUZA E SILVA, 2011, p. 137)

Partimos da ciência de tais muros invisíveis e eficientes que ainda restringem o acesso e permanência de jovens periféricos nas universidades, 
DAEMON, Flora; MENDONÇA, Kleber; NERCOLINI, Marildo. "Quem Sabe de Mim Sou Eu": práticas culturais e comunicacionais como

instrumentos pedagógicos junto a jovens em vulnerabilidade.

PragMATIZES - Revista Latino-Americana de Estudos em Cultura,

Niterói/RJ, Ano 11, n. 20, p. 109-135, março 2021.

bem como do impacto das políticas de ação afirmativa, como as cotas, para pleitear uma defesa: acreditamos que a renovação da universidade não deva passar pela adaptação dos indivíduos que a compõe e justificam. Ao contrário, se a universidade quer ser, de fato, um lugar de potencialização do conhecimento e de formação de quadros necessários para a sociedade, será ela quem precisará se adequar. A questão que permanece é: afinal, quem é a universidade? As ainda minoritárias, porém insurgentes presenças periféricas, alinhadas com aqueles que, mesmo não partindo das mesmas condições de vulnerabilidade, têm um papel histórico nesta luta. Quem Sabe de Mim Sou Eu parte e permanece alinhado a esse desafio.

\section{Referências bibliográficas}

ENNE, Ana Lucia;. PASSOS, Pâmella. Juventudes e apropriações urbanas em uma leitura polissêmica. Políticas Culturais em Revista, Salvador, v. 11, n. 2, p. 123-145, jul./dez. 2018.

FAUSTINI, Marcus Vinícius. Considerações iniciais sobre juventude, cultura e território. In: SOUZA E SILVA, Jailson; BARBOSA, Jorge; FAUSTINI, Marcus (orgs.). O novo carioca. Rio de Janeiro: Mórula, 2012.
FOUCAULT, Michel. Vigiar e Punir: nascimento da prisão. Petrópolis: Vozes, 1987.

GEERTZ, Clifford. A interpretação das culturas. Rio de Janeiro: LTC, 1989.

GOFFMAN, Erving. Estigma: notas sobre a manipulação da identidade deteriorada. Rio de Janeiro: LTC, 2008.

HALBWACHS, Maurice. A memória coletiva. São Paulo: Vértice, 1990.

HOOKS, bell. Ensinando a transgredir: a Educação como prática de liberdade. São Paulo: Martins Fontes, 2013.

KANT DE LIMA, Roberto. A administração dos conflitos no Brasil: a lógica da punição. In: Velho, Gilberto; ALVITO, Marcos (orgs.). Cidadania e Violência. Rio de Janeiro: UFRJ/FGV, 1996.

MACHADO SILVA, Luiz Antônio. Vida sob cerco: violência e rotina nas favelas do Rio de Janeiro. Rio de Janeiro: Nova Fronteira, 2008.

MASSEY, D. Pelo Espaço: uma nova política da espacialidade. Rio de Janeiro: Bertrand Brasil, 2008.

MISSE, Michel. Sobre a acumulação social da violência no Rio de Janeiro. Civitas, Porto Alegre, No 8, Vol. 3; setdez. 2008.

POLLAK, Michael. Memória e identidade social. Revista Estudos Históricos, 10, 1992/1. Disponível em: http://www.cpdoc.fgv.br/revista/arq/104 .pdf.

RIBEIRO, Darcy. O Povo Brasileiro. São Paulo: Cia das Letras, 1995.

SOARES, Luiz Eduardo; BILL, MV; ATHAYDE, Celso. Cabeça de porco. Rio de Janeiro: Objetiva, 2005. 
SOUZA E SILVA, Jailson. "Por que uns e não outros?" Caminhada de jovens pobres para a universidade. Rio de Janeiro: 7Letras, 2011.

VALLADARES, Lícia. A invenção da favela: do mito de origem a favela.com. Rio de Janeiro FGV, 2005.

VALLADARES, Lícia. Educação e mobilidade social nas favelas do Rio de Janeiro: o caso dos universitários (graduandos e graduados) das favelas. Dilemas: Revista de Estudos de Conflito e Controle Social. Vol. 2 - no 5-6 - jul-dez 2010.

VELHO, Gilberto. Individualismo e Cultura: Notas para uma Antropologia da Sociedade Contemporânea. Rio de Janeiro: Zahar, 1987.

VELHO, Gilberto. Projeto e Metamorfose: Antropologia das sociedades complexas. Rio de Janeiro: Zahar, 1994.

WILLIAMS, Raymond. Cultura e materialismo. São Paulo: UNESP, 2011.

ZALUAR, Alba; ALVITO, Marcos (orgs.). Um século de favela. Rio de Janeiro: FGV, 2006. 